\title{
LIVE MARKETING EXISTE? REFLEXÕES SOBRE IMBRICAMENTOS E TENSÕES COM A PUBLICIDADE
}

\author{
Does live marketing exist? Reflections about overlappings and \\ tensions with advertising \\ ¿Hay live marketing? Reflexiones sobre imbricaciones y \\ tensiones con la publicidad
}

\author{
Fernanda Ferreira de Abreu \\ Universidade Federal Fluminense, Rio de Janeiro, Brasil. \\ Professora Adjunta do Departamento de Comunicação Social da Universidade Federal Fluminense. Integrante \\ do Grupo de Pesquisa em Retórica do Consumo da Universidade Federal Fluminense e do Conselho Nacional \\ de Desenvolvimento Científico e Tecnológico. \\ E-mail: feabreu82@hotmail.com
}

RESUMO Na contemporaneidade, marcada pela multiplicação e fragmentação de oportunidades de contato com os públicos consumidores, complexifica-se a relação da publicidade com as demais ferramentas de comunicação. Este artigo reflete sobre o live marketing, termo que passou a ser utilizado no mercado brasileiro nos últimos anos como uma atualização de marketing promocional. Percebe-se que o live marketing se define em oposição à publicidade, e discute-se a validade dessa separação tendo em vista um contexto em que a própria publicidade se transforma.

PALAVRAS-CHAVE Live marketing, Publicidade, Ciberpublicidade, Comunicação integrada de marketing, Ecossistema publicitário.

ABSTRACT In contemporary times, marked by the multiplication and fragmentation of opportunities to contact with consumers, the relationship between advertising and other communication tools becomes more complex. This article reflects on live marketing, term that became used in Brazilian market in recent years as an update of promotional marketing. It is perceived that live marketing is defined opposed to advertising, and the validity of this separation is discussed considering a context in which advertising itself is transformed.

KEYWORDS Live marketing, Advertising, Cyber advertising, Integrated marketing communication, Advertising ecosystem.

RESUMEN En la época contemporánea, marcada por la multiplicación y la fragmentación de las oportunidades de contacto con el público consumidor, la relación de la publicidad con otras herramientas de comunicación se hace más compleja. En este artículo se reflexiona sobre el término live marketing, que llegó a ser utilizado en el mercado brasileño en los últimos años como una actualización de marketing promocional. Se observa que el live marketing se define en oposición a la publicidad y se discute la validez de esa separación a la vista del contexto en el que se transforma la propia publicidad.

PALABRAS CLAVE Live marketing, Publicidad, Ciberpublicidad, Comunicación integrada de marketing, Ecosistema publicitario. 


\section{INTRODUÇÃO}

É inegável que a publicidade tem passado por inúmeras transformações no século atual, sobretudo em função da intensificação do uso da internet e dos dispositivos digitais. Diferentes termos têm sido criados no âmbito acadêmico para dar conta dessas mudanças, tal como mapeia Perez (2016a). Entre eles, pode-se mencionar "ciberpublicidade" (ATEM; OLIVEIRA; AZEVEDO, 2014), que se define em oposição ao modelo tradicional de publicidade, caracterizado pela comunicação unidirecional com um público consumidor, utilizando-se, para tanto, de meios de comunicação de massa, em consonância com a fórmula tão presente em manuais de publicidade e marketing: AIDA (acrônimo de Atenção, Interesse, Desejo e Ação). Esse modelo parte do pressuposto de que uma campanha publicitária de sucesso percorrerá com eficácia essas etapas que culminarão numa ação - normalmente a aquisição de um produto ou serviço.

Com a multiplicação e fragmentação das oportunidades de contato (ANDERSON, 2006), além da propalada Web 2.0 em associação com a transformação de consumidores em prosumers (TAPSCOTT; WILLIAMS, 2007), o processo publicitário se complexifica; e ao esquema AIDA é proposto pelos autores que cunharam o termo ciberpublicidade o acréscimo da "tríade interatividade-relevância-experiência" (ATEM; OLIVEIRA; AZEVEDO, 2014, p. 10), uma vez que se torna cada vez mais difícil capturar a atenção e envolver o público consumidor. É a essa tríade que o radical "ciber" remete. A ciberpublicidade não se restringe, assim, à publicidade veiculada na internet - até porque as divisões entre on e off tornam-se cada vez mais borradas -, mas a um novo modo de se trabalhar a publicidade.

No atual cenário, não são só as fronteiras entre o que é ou não digital que se confundem, mas também as linhas divisórias estabelecidas entre as próprias ferramentas de comunicação. Diante da diversidade de ferramentas e meios de comunicação, é fundamental que as empresas atentem para a transmissão de uma mensagem coerente em todos os pontos de contato com o seu público-alvo, sob o risco de transmitir um posicionamento confuso se não prezar pela integração.

Dessa forma, após uma breve explanação acerca do conceito de comunicação integrada de marketing, será abordada a noção de live marketing - lançada oficialmente pela Associação de Marketing Promocional (Ampro) em 2013 -, que aglutinaria algumas ferramentas de comunicação, definindo-se em oposição à publicidade e como uma atualização do marketing promocional. O objetivo principal deste artigo consiste, portanto, em discutir a validade do termo e suas relações com a publicidade, sobretudo a partir do que propõe o livro Do marketing promocional ao live marketing, escrito por Tony Coelho (2015), profissional da área e um dos principais difusores dessa nomenclatura, cujo intuito é ampliar a importância das atividades promocionais no composto de comunicação de marketing, aproveitando-se das mudanças que têm ocorrido.

A ideia para o texto surgiu de uma colocação de Coelho (Ibidem, p. 152) de que não conseguia emplacar o termo live marketing no meio acadêmico, ouvindo de professores que ele não existia e nunca existiria. É importante esclarecer que não se tem a pretensão, com este texto, de promover e defender o live marketing no âmbito acadêmico. Contudo, não há como negar sua utilização crescente no mercado brasileiro e em 
veículos de comunicação que são referências nessa área, como Meio \& Mensagem e Adnews. A título de exemplificação, recentemente foi publicada uma matéria sobre o que as grandes marcas esperam do marketing, com o seguinte depoimento de Luciano de Sá, gerente de marketing sênior da Coca-Cola Femsa:

Um dos principais desafios é estreitar ainda mais o caminho até o target por meio de estratégias segmentadas e voltadas para um objetivo transacional. Ações de Live Marketing se apresentam como peça-chave no contato com o público. Além de ser a melhor forma de abordar o call-to-action, trabalha com experiência personalizada, e não com a massificação apontada pela grande maioria das mídias (PACETE, 2017).

Não há como refutar, portanto, a existência e utilização do termo, e não mais apenas por profissionais vinculados à Ampro, mas também pelos próprios anunciantes. Entretanto, pode-se certamente questionar sua validade e pertinência, além de seu papel no composto comunicacional de marketing. A propagação que o termo live marketing aos poucos conquista no mercado brasileiro merece, assim, uma discussão mais aprofundada, que venha a extrapolar os limites deste artigo.

\section{COMUNICAÇÃO INTEGRADA DE MARKETING (CIM)}

De acordo com Kotler e Armstrong (2015), o novo mundo do marketing digital, dos tablets, smartphones e aplicativos, traz não apenas grandes oportunidades, mas também enormes desafios, entre os quais é destacado o de se organizar diante da complexidade e da fragmentação. "Por conta disso, muitas empresas adotam o conceito de comunicação integrada de marketing (CIM). Segundo esse conceito, a empresa integra, cuidadosamente, seus diversos canais de comunicação a fim de transmitir uma mensagem clara, consistente e persuasiva” (Ibidem, p. 453).

Conforme ressaltam Ogden e Crescitelli (2007), o que assegura essa integração é, além da adequação ao público-alvo, a transmissão de um mesmo tema (ou ideia) central, ou de um conceito de comunicação invariável, em todos os pontos de contato. Entre os exemplos fornecidos pelos autores de como a transmissão de um mesmo conceito por diversas ferramentas e mídias é um importante aliado na construção de um posicionamento sólido, ganha destaque a campanha Priceless ("Não Tem Preço”) da MasterCard, em uso desde 1997, quando deflagrada nos Estados Unidos, sendo lançada no Brasil em 1999.

Se a busca por transmitir mensagens relevantes ao público-alvo, que expressem um mesmo tema central, já representa um desafio, o mesmo pode ser dito em relação à escolha dos pontos de contato. A dificuldade começa na própria identificação das modalidades, formas ou ferramentas de comunicação. Dificilmente, ao se comparar textos de dois autores, será encontrada exatamente a mesma classificação, como pode ser verificado ao se contrapor, por exemplo, a categorização proposta em Kotler e Armstrong (2015), Ogden e Crescitelli (2007) e Sá et al. (2010).

Até mesmo ao confrontar as últimas edições dos livros Princípios de Marketing e Administração de Marketing, ambos com a coautoria de Kotler, são encontradas diferenças. No primeiro, consta que "o composto total de uma empresa - também chamado de composto de comunicação de marketing - consiste na combinação específica de ferramentas de propaganda, relações públicas, venda pessoal, promoção de vendas e 
marketing direto" (KOTLER; ARMSTRONG, 2015, p. 448). Já no segundo livro, a essas cinco ferramentas acrescentam-se: eventos e experiências, marketing interativo (ou digital) e marketing boca a boca (KOTLER; KELLER, 2012, p. 514).

Cabe indicar que Kotler e Armstrong (2015, p. 449) consideram publicidade como sinônimo de relações públicas, ao passo que no mercado brasileiro considera-se publicidade como sinônimo de propaganda, assim definida pelos autores: "qualquer forma paga de apresentação e promoção não pessoais de ideias, produtos ou serviços feita por um patrocinador identificado”. Conforme é esclarecido por Sá et al. (2010, p. 58), “no Brasil, o Conselho Executivo de Normas-Padrão (Cenp), que normatiza essas áreas, considera publicidade como sinônimo de propaganda, ou seja, o ato de veicular anúncios pagos”. Como o termo publicidade é inclusive mais utilizado, não só no mercado brasileiro como também na academia, ele será empregado neste texto para se referir ao que Kotler e seus coautores definem, em ambos os livros citados, como propaganda.

Foge ao nosso escopo apresentar e discutir as definições de cada uma das ferramentas mencionadas. Contudo, é importante ressaltar que as dificuldades de classificação não se referem apenas ao número de ferramentas detectadas, mas sobretudo ao fato de as fronteiras entre elas serem tênues e imprecisas, especialmente ao se analisar a práxis em sua dinamicidade. Em função disso, foi elaborado, por exemplo, o conceito de publicidade híbrida, utilizado por Covaleski (2010, p. 17, grifo no original) para se referir ao que compreende como um novo produto midiático: "o entretenimento publicitário interativo, pois são híbridos que, em um mesmo esforço comunicacional, persuadem, entretêm, interagem e são, de alguma forma, compartilháveis.”.

Desse modo, por mais que classificações sejam necessárias para a organização do composto comunicacional e sua estruturação no mercado de trabalho, é fundamental considerar a fragilidade de suas fronteiras, já que o processo de hibridização se faz necessário para a sobrevivência da própria atividade publicitária. Conforme coloca Donaton (2007, p. 15), em livro cujo título já é bastante sugestivo, Publicidade + Entretenimento: por que estas duas indústrias precisam se unir para garantir a sobrevivência mútua, "o que terminou para valer com a velha desconfiança e as resistências para que esse relacionamento [Publicidade + Entretenimento] engrenasse foi, entre outros fatores, o medo comum às tecnologias digitais". Como exemplos dessas reconfigurações que esgarçam fronteiras, pode-se mencionar o Product Placement, o Branded Content e o Advertainment, conforme mapeados por Viana (2016).

Esses formatos híbridos ganham destaque, portanto, num contexto em que se intensifica a utilização das tecnologias digitais. Conforme já foi visto, na concepção da ciberpublicidade, a "tríade interatividaderelevância-experiência” (ATEM; OLIVEIRA; AZEVEDO, 2014, p. 10) adquire importância; e a associação com o entretenimento - que aparece em Kotler e Keller (2012, p. 515) como parte da ferramenta "eventos e experiências" - favoreceria a conquista desses atributos. De acordo com Donaton (2007, p. 21),

o que está em jogo não é nada menos do que a reinvenção do negócio da comunicação do marketing, e para isso é necessária uma mudança total de mentalidade, de um modelo baseado na intrusão a um modelo estruturado no convite e na sedução do consumidor. 
Se, por um lado, a publicidade tem se reconfigurado ao se associar com outras ferramentas de comunicação, de modo a ser menos interruptiva e mais envolvente; por outro, há tentativas de se exaltar os benefícios das demais ferramentas - como os eventos, por exemplo - colocandoas em contraste com a publicidade, porém com um modelo tradicional de publicidade, caracterizado sobretudo pela intrusão e comunicação unidirecional, modelo este que se torna cada vez mais difícil de acessar em seu estado "puro".

\section{LIVE MARKETING}

Entre essas tentativas de aclamar ferramentas colocando-as em oposição à publicidade, merece relevo o esforço feito pela Associação de Marketing Promocional (Ampro) desde 2013 para alavancar o conceito de live marketing. Coelho (2015), membro da Diretoria Regional Sudeste da Ampro, em livro cujo objetivo é justamente defender o novo conceito, traça um percurso do below the line (cuja tradução literal é "abaixo da linha”) ao live marketing. A expressão below the line (BTL) teria sido inventada na década de 1950, nos Estados Unidos, para se referir às ações não mídia, isto é, às ações que não implicavam custos de veiculação, em contraposição aos anúncios pagos em televisão, rádio, mídia impressa, cinema e outdoor, que envolvem não apenas custos de criação e produção, mas o pagamento pelos espaços de comunicação.

Os termos below e não mídia conferem, assim, uma conotação negativa, indicando um papel secundário ou uma ausência, o que Coelho (2015) sinaliza que poderia até fazer sentido naquela época. As agências de promoção, ações no ponto de venda e eventos eram chamadas de agências de BTL e foram criadas a partir do desinteresse das agências de publicidade nessas disciplinas, por demandarem muito trabalho e trazerem pouco retorno financeiro. Os departamentos de promoção e eventos foram então fechados nas agências de publicidade e seus profissionais passaram a ser fornecedores.

$\mathrm{Na}$ verdade, as ações nessas ferramentas continuaram a ser criadas pelas agências de publicidade e às agências de BTL cabia a função de executá-las, sem que tivessem contato direto com os anunciantes. Coelho (2015) indica que aos poucos essa situação se transformou e as agências de BTL passaram a oferecer ideias de eventos e ações diferenciadas diretamente aos anunciantes, até que em 1993 surgiu a Ampro para representar os interesses dessas empresas e sustentar que, muito mais do que below the line, eram agências de marketing promocional.

Nesse contexto, é publicado o livro Marketing promocional: a evolução da promoção de vendas, de João De Simoni Ferraciù (2007), fundador da Ampro. De acordo com esse autor, a promoção de vendas - definida por Kotler e Armstrong (2015, p. 449) como "incentivos de curto prazo para estimular a compra ou a venda de um produto ou serviço" - integra-se a um complexo denominado marketing promocional, ou seja, a "uma operação de planejamento estratégico ou tático combinando, sinérgica e sincronizadamente, as ações de promoção de vendas com uma ou mais disciplinas das outras comunicações multidisciplinares de marketing” (FERRACIÙ, 2007, p. 12).

É sustentado ainda que "não há, e não pode haver, marketing promocional sem que a essência se baseie numa ideia ou ação de promoção de vendas” (Ibidem, p. 13). As ferramentas a que a promoção de vendas recorre podem ser diversas, conforme cita o autor: publicidade 
ou propaganda, marketing direto, eventos, relações públicas etc. É ainda mencionado por Ferraciù - para explicitar a diferença entre promoção de vendas e marketing promocional - que a promoção de vendas se caracteriza como uma disciplina isolada, ao passo que o marketing promocional precisa necessariamente utilizar outras ferramentas da comunicação de marketing.

É interessante observar como no livro de Coelho (2015, p. 32-34) acerca do live marketing, ao se mencionar as disciplinas que compõem o marketing promocional, diferentemente de Ferraciù (2007), não se faz nenhuma menção à publicidade. Ganham destaque, além da promoção de vendas (e suas técnicas variadas, como concurso, sorteio, vale-brinde, cupom de desconto etc.), o merchandising no ponto de venda, os eventos e as ações de incentivo (como troca de prêmios por pontos acumulados e concursos de vendas). De fato, não faria muito sentido incluir a publicidade, já que a proposta do live marketing - que se dispõe a "acrescentar um toque de atualidade ao que já é conhecido", isto é, ao marketing promocional (COELHO, 2015, p. 9) - é conferir representatividade e destaque às disciplinas que não seriam classificadas como publicidade.

Neste contexto, em que a publicidade precisa se transformar e para isso se hibridiza, havendo assim uma tendência de as agências de publicidade se autodenominarem agências de comunicação ou de comunicação integrada - entre outras nomenclaturas, como full service e $360^{\circ}$-, incorporando o que já foi segregado e classificado como below the line, os profissionais de promoção e eventos, e de outras atividades comunicacionais que adquirem maior relevância na atualidade em função da experiência que podem proporcionar, não querem ser simplesmente incorporados novamente pelas agências de publicidade.

Nas palavras de Coelho (2015, p. 37), "A questão impunha uma atitude rápida em defesa de nossas atividades, porque se nada fosse feito voltaríamos a ter o papel de coadjuvantes executores de projetos”. Dessa forma, em julho de 2013, foi realizado o $1^{\circ}$ Congresso Brasileiro de Live Marketing, que teria sacramentado, conforme defende o autor, o surgimento do termo. Ao congresso, que teve sua segunda edição em 2015, somaram-se as seguintes iniciativas capitaneadas pela Ampro: anuário, revista (em edição impressa e digital) e cursos de formação de profissionais.

Coelho (2015, p. 38) aponta que, na verdade, o termo live marketing não é algo novo, e diz que uma agência gaúcha, não mais em atividade, já utilizava essa nomenclatura há cerca de dez anos; e que um profissional ao integrar a AlmapBBDO - renomada agência de publicidade -, para cuidar da área de promoção, batizou seu departamento de Live Marketing. Foi daí que o nome chegou à presidência da Ampro.

Live significa "ao vivo" em inglês, e é essa característica que se deseja ressaltar. Coelho (Ibidem, p. 40) sinaliza que a definição de live marketing transita no Grupo de Estudos Acadêmicos da Ampro e fornece uma definição provisória para favorecer a compreensão de seus leitores:

Disciplina de comunicação que abrange todas as ações, eventos ou campanhas nas quais o consumidor ou shopper está numa relação direta de compra, real ou virtual, de conceitos de marca, de produto ou serviço, ao vivo. Estrategicamente, promove experiência de marca, através dos sentidos, aproximando-a de seus consumidores, gerando venda ou aumento de valor 
Atualmente, consta no site da Ampro (2017) a seguinte definição:

É a atividade de comunicação onde se incluem todas as ações, campanhas ou eventos que proporcionem experiência de marca e interação para, de forma estratégica, se atingir resultados e soluções de comunicação para marcas produtos e serviços. É o guarda-chuva onde se inserem todas as ações, eventos e campanhas que aconteçam ao vivo na relação do consumidor ou shopper com marca, produto ou serviço

Coelho (2015, p. 12) indica ainda que o live marketing compreende ações comunicacionais que podem ser classificadas em cinco modalidades: digital, evento, incentivo, merchandising (no ponto de venda) e promoção. Percebe-se, assim, que às modalidades a que já se havia referido quanto à definição de marketing promocional, foi acrescentado o digital. Coelho (Ibidem, p. 42) pontua - sem, de fato, explicar - que o live marketing engloba "parte do conceito estratégico do Marketing Digital”. Para adquirir a importância almejada no atual cenário, a Ampro não teria como abrir mão do digital. Em tempos de transmissão ao vivo pelo Facebook, por exemplo, a própria noção de "ao vivo” se reconfigura, o que demandaria uma análise mais aprofundada. É somente mencionado que o "ao vivo" vincula-se ao fato de que, se errar, tem que consertar na hora (Ibidem).

Para o propósito deste artigo, cabe destacar as principais características do que os profissionais filiados à Ampro definem como live marketing: proporciona experiência - por meio da sinestesia -, interatividade e proximidade. Convém retomar, assim, a "tríade interatividade-relevânciaexperiência” (ATEM; OLIVEIRA; AZEVEDO, 2014, p. 10), a que se aludiu no início deste artigo em referência à ciberpublicidade; e questionar se o live marketing não estaria, então, mais propenso a capturar a atenção e conquistar o engajamento do público consumidor em comparação com a publicidade.

\section{PUBLICIDADE E/OU LIVE MARKETING?}

Deparamo-nos com um “campo", no sentido proposto por Bourdieu (1983, p. 89), que foca objetos de disputas de grupos que possuem interesses próprios e específicos. De acordo com este autor, "para que um campo funcione, é preciso que haja objetos de disputas e pessoas prontas para disputar o jogo, dotadas de habitus que impliquem no conhecimento e no reconhecimento das leis imanentes do jogo, dos objetos de disputa etc.”. Pelo que foi exposto acima, não resta dúvida de que há uma disputa entre os profissionais de comunicação pelo que melhor funcione para se capturar a atenção do público-alvo num contexto em que ela se torna cada vez mais difícil de obter. Não será possível mapear todo esse campo e suas diferentes configurações, contudo, cabe fornecer algumas pistas.

Entre os prêmios concedidos aos publicitários no mercado brasileiro, destaca-se o Caboré, criado em 1980 pelo jornal Meio \& Mensagem. $\mathrm{Na}$ edição de 2016, a Publicis ganhou o título de melhor agência de comunicação. Nota-se que se trata de agência de comunicação, e até 2010 a categoria era agência de propaganda. De 2011 a 2014, constava agência, apenas. Foi a partir de 2015 que a categoria passou a se chamar agência de comunicação, o que não deixa de ser sugestivo.

Ao se entrar no site da Publicis Brasil, há uma seção com as expertises da agência, entre as quais aparece em primeiro lugar a publicidade. 
Contudo, há dezessete outras áreas de especialidade, como branded content e marketing promocional, apenas para citar termos aludidos ao longo deste artigo. É curioso que, além da menção a ferramentas de comunicação específicas, aparece, entre as expertises, o marketing integrado, com a seguinte definição: "de acordo com suas metas, recomendamos os melhores canais de comunicação, entregando uma eficiente arquitetura global de marketing capaz de reverberar mensagens que levam em conta a estratégia da marca e os insights de consumo" (PUBLICIS BRASIL, 2017). Ou seja, além de ter competência para prestar serviços aos anunciantes nas mais diversas modalidades de comunicação, a agência opta por frisar que também é capacitada para promover a integração entre essas ferramentas.

Live marketing não aparece entre as expertises da Publicis. Contudo, na campanha que fez para angariar votos para o prêmio, uma vez que foi indicada com outras duas agências, ressaltou-se a ação de live marketing inédita criada para a marca Oral- $\mathrm{B}^{1}$, a qual já era patrocinadora do programa The Voice Brasil, da TV Globo, e buscava uma forma de se estabelecer nas mídias sociais. Para tanto, contrataram uma exparticipante do programa, muito querida pelo público, para interagir em real time no Twitter quando o programa estivesse ao vivo, com a hashtag "o poder do sorriso", que é o tema central trabalhado pela Oral-B em diferentes pontos de contato. Ao longo da temporada de 2016, essa iniciativa esteve entre os trending topics oito vezes ${ }^{2}$. Percebe-se que a expressão "ao vivo" é utilizada na descrição da ação, e justamente por isso ela deve ter sido classificada como live marketing.

Ao considerar as cinco modalidades de live marketing propostas por Coelho (2015), esse caso da Oral-B seria enquadrado como digital, já que não se trata de evento, de promoção de vendas, de merchandising no ponto de venda e nem de um programa de incentivo. Por outro lado, é importante notar que não foi uma ação isolada, mas que surgiu a partir do patrocínio de um programa de TV - que, entre as ferramentas comunicacionais descritas por Kotler e Keller (2012), se enquadraria em propaganda. Ressalta-se, porém, que a interação ao vivo no Twitter extrapolou uma definição restrita de propaganda (ou publicidade), favorecendo o alcance do que a publicidade tem buscado no atual cenário: interatividade, experiência e relevância.

Na Revista Live Marketing, iniciativa da Ampro, é difícil achar um exemplo de ação que não trabalhe também com publicidade - mesmo em seu sentido estrito, de anúncio pago -, nem que seja utilizada para potencializar a divulgação. Ações de promoção de vendas precisam, desse modo, da publicidade, especialmente para se tornarem conhecidas, assim como acontece no caso dos eventos. Além da seção "promoção e eventos", o site da Revista Live Marketing contempla outros dois canais: digital e incentivo ${ }^{3}$.

Para continuarmos no âmbito do digital, ainda que se acredite que essa divisão não deva ser tão marcada, aparece a campanha de carnaval 2017 da marca de camisinha Blowtex, que conta com o uso de influenciadores digitais. Consta o seguinte trecho: "Youtubers como PC Siqueira, Maicon Santini e Victor Meyniel surgirão em diversas

1. Disponível em: <goo.gl/vGttPj>. Acesso em: 24 nov. 2016.

2. Video case disponível em: <goo.gl/ZAT9xX>. Acesso em: 17 fev. 2017.

3. Disponível em: <goo.gl/i4L7g7>. Acesso em: 13 fev. 2017. 
situações para ilustrar os sete estilos trabalhados dentro da nova comunicação de Blowtex com o mercado.” (REVISTA LIVE MARKETING, 2017). Nesse caso, não há nenhuma menção acerca do caráter ao vivo da ação. Vídeos, como "Sexo com o crush” de PC Siqueira - com quatro minutos e meio de duração -, são gravados e divulgados no canal do influenciador, bem como no canal da Blowtex no YouTube. Fica claro que se trata de um conteúdo patrocinado, já que PC Siqueira diz logo no início da gravação "Eu fui convidado pela Blowtex nesse vídeo para falar sobre paquera”"

Para este propósito, cabe questionar se, mesmo sem a dimensão do "ao vivo”, a ação acima se configura como live marketing. Ou seja, toda ação de comunicação que não é publicidade no sentido restrito, isto é, de um anúncio que interrompe o conteúdo do veículo, que apresenta um custo de veiculação ou de mídia, e cuja comunicação é unidirecional, enquadra-se como live marketing? Se assim for, é importante sinalizar que o dinamismo do mercado está sendo ignorado. A própria publicidade tem se reconfigurado a cada dia. Em função disso, Perez (2016b, p. 50) se refere a "ferramentas e estratégias do ecossistema publicitário", fundamentais para a expressão das marcas.

As marcas se expressam, se dão a ver, se mostram de diversas maneiras, com o objetivo de potencializar seus efeitos de sentido e facilitar os vínculos com as pessoas. Esses elementos de expressão marcária são levados às mídias audiovisual ou só de áudio, impressa, exterior, digital, às ruas, comunidades, com a intenção de penetrar em nossos sentidos e causar sensações agradáveis e até afetivas que nos levem a uma aproximação. 0 objetivo é estabelecer uma conexão - e se esta for emocional, tanto melhor (Ibidem, p. 49)

A publicidade - ou melhor, o ecossistema publicitário, à medida que se entende a publicidade em toda a sua complexidade midiática - seria assim fundamental para a disseminação dos símbolos marcários. Nas palavras de Perez (Ibidem, p. 122), "O caminho para explicitar essas expressividades e sensorialidades é a publicidade - ela traz vida à marca”. Do mesmo modo que publicidade não é entendida em sentido restrito, o mesmo é feito em relação às mídias, que passam a ser compreendidas como "pontos de conexão" - e assim são denominadas por grandes anunciantes, como a Coca-Cola -, não se restringindo aos meios de comunicação e formatos considerados tradicionais.

As ideias colocadas em prática que busquem esta relação (pessoasmarcas) pertencem ao ecossistema publicitário. Assim, os conceitos de promoção, merchandising, insert, product placement, gameficação, blitz, ativação, marketing de relacionamento, branded content, loja conceito, flashmobs, apps, etc, bem como suas estruturas e suportes (internet, tv, rádio, cinema, rua, casa, todas as telas e tudo o mais que surgir) integram esta Ecologia. Não apenas anunciante - agência - veículo, agora temos os mais diferentes parceiros na construção e implementação das soluções: empresas de infraestrutura, de sistemas sofisticados de algoritmos, de monitoramento de redes sociais, de robótica, eventos, empresas de conteúdo etc. (PEREZ, 2016a, p. 9, grifo meu)

4. Disponível em: <goo.gl/MV0ZQb>. Publicado em: 3 fev. 2017. Acesso em: 20 fev. 2017. 
Perez (2016b, p. 42) também ressalta que "há um crescente transbordamento das expressividades marcárias para caminhos mais sensíveis, como signos sonoros, olfativos, táteis e mesmo gustativos”. Na semiótica da expressividade marcária proposta pela autora, com base na semiótica peirceana, a marca é considerada signo junto com fragrância, sabor, textura, jingle, publicidade etc. Nessa perspectiva, não faz sentido falar em live marketing, uma vez que a ênfase na experiência e nos sentidos - trabalhados, por exemplo, em eventos e ações no ponto de venda, favorecendo uma interação ao vivo - já estaria contemplada no ecossistema publicitário.

Não caberia, portanto, dividir as ações comunicacionais em publicidade e live marketing, mas em considerar o que seria melhor para a expressão marcária. De acordo com Perez (2016b), para uma marca não entrar em entropia - o que a levaria à degradação -, é preciso investir em comunicação, mas em comunicação atualizada em relação ao públicoalvo. Ou seja, a insistência em modelos de comunicação já desgastados levaria a marca à entropia, o que demanda uma transformação da própria publicidade.

Por outro lado, profissionais - contemplados entre os parceiros a que Perez (2016a) alude - especializados, por exemplo, em eventos, promoções e ações no ponto de venda, ou seja, em práticas que favoreceriam a produção de experiência, interatividade e relevância, não desejam ser abarcados mais uma vez pela publicidade e por quem a exerce. E isso os motiva a propagar a nomenclatura live marketing.

\section{CONSIDERAÇÕES FINAIS}

Longe de esgotar a apresentação e discussão do conceito de live marketing, o intento foi iniciar o debate, e mostrar como as definições nos escapam e as fronteiras se confundem num cenário em que a publicidade tradicional, baseada na comunicação unidirecional, deixa de fazer sentido. Conceitos como o de comunicação integrada de marketing e ecossistema publicitário resolvem o problema na medida em que englobam todas as ferramentas de comunicação e suas variações em uma ambiência integradora. Parece não haver dúvidas de que a integração é essencial para a expressão marcária, assim como a utilização de ações comunicacionais que proporcionem interatividade, relevância e experiência, envolvendo nossos diferentes sentidos.

Contudo, quando nos voltamos para o mercado de trabalho, esse processo se complexifica ao passo que abrange pessoas com interesses conflitantes. Os profissionais que se autointitulam especialistas em live marketing se definem em contraposição ao modelo tradicional de publicidade, que se torna cada vez mais difícil de identificar no atual contexto. Talvez precisem fazer isso para que a estratégia comunicacional não continue a ser dirigida pelos profissionais das agências de publicidade, agora que as ferramentas em que são especializados ganham importância.

Mas não haveria outro caminho pelo viés da integração - e não da separação - que considere as transformações por que passa a publicidade? Cabe a nós acompanharmos se o termo live marketing terá fôlego e continuarmos a discutir esses arranjos do mercado, o que envolve aspectos referentes à própria formação do profissional de comunicação e/ou de publicidade e propaganda. 


\section{REFERÊNCIAS}

ASSOCIAÇÃO DE MARKETING PROMOCIONAL (AMPRO). Live Marketing. São Paulo, 2017. Disponível em: <goo.gl/OugQOW>. Acesso em: 16 fev. 2017.

ANDERSON, C. A cauda longa: do mercado de massa para o mercado de nicho. Rio de Janeiro: Elsevier, 2006.

ATEM, G. N.; OLIVEIRA, T. M.; AZEVEDO, S. T. (Orgs.). Ciberpublicidade: discurso, consumo e experiência na cultura transmidiática. Rio de Janeiro: E-Papers, 2014.

BOURDIEU, P. Algumas propriedades dos campos. In: Questões de sociologia. Rio de Janeiro: Marco Zero, 1983. p. 89-94.

COELHO, T. Do marketing promocional ao live marketing. São Caetano do Sul: Abccom editora, 2015.

COVALESKI, R. O processo de hibridização da publicidade: entreter e persuadir para interagir e compartilhar. 2010. 176 f. Tese (Doutorado em Comunicação e Semiótica) - Pontifícia Universidade Católica de São Paulo, São Paulo, 2010.

DONATON, S. Publicidade + Entretenimento: por que estas duas indústrias precisam se unir para garantir a sobrevivência mútua. São Paulo: Cultrix, 2007.

FERRACIÙ, J. S. Marketing promocional: a evolução da promoção de vendas. 6. ed. São Paulo: Pearson Prentice Hall, 2007.

KOTLER, P.; ARMSTRONG, G. Princípios de marketing. 15. ed. São Paulo: Pearson Prentice Hall, 2015.

KOTLER, P.; KELLER, K. Administração de marketing. 14. ed. São Paulo: Pearson Education do Brasil, 2012.

OGDEN, J. R.; CRESCITELLI, E. Comunicação integrada de marketing: conceitos, técnicas e práticas. 2. ed. São Paulo: Pearson Prentice Hall, 2007.

PACETE, L. G. O que as grandes marcas esperam do marketing. Meio \& Mensagem, São Paulo, 10 fev. 2017. Disponível em: <goo.gl//GRHRH>. Acesso em: 10 fev. 2017.

PEREZ, C. Ecossistema publicitário: o crescimento sígnico da publicidade. In: Congresso Brasileiro de Ciências da Comunicação, 39., São Paulo, 2016. Anais... São Paulo, 2016a. Disponível em: <goo.gl/TBz2nc>. Acesso em: 6 fev. 2017.

Signos da marca: expressividade e sensorialidade. 2. ed. São Paulo: Cengage Learning, 2016b.

PUBLICIS BRASIL. Expertises. Publicis, São Paulo, 2017. Disponível em: <goo.gl/lq47mv>. Acesso em: 17 fev. 2017.

REVISTA LIVE MARKETING. Campanha de Carnaval da Blowtex conta com influenciadores digitais. Revista Live Marketing, São Paulo, 14 fev. 2017. Disponível em: <goo.gl/2N3r9t>. Acesso em: 20 fev. 2017.

SÁ, P. R. G. et al. Comunicação integrada de marketing. Rio de Janeiro: Editora FGV, 2010.

TAPSCOTT, D.; WILLIAMS, A. Wikinomics: como a colaboração em massa pode mudar o seu negócio. Rio de Janeiro: Nova Fronteira, 2007.

VIANA, P. M. F. Do product placement ao branded content: uma revisão bibliográfica a partir da base de dados Scopus. In: Congresso Brasileiro de Ciências da Comunicação, 39. São Paulo, 2016. Anais... São Paulo, 2016. Disponível em: <goo.gl/dTVMdQ>. Acesso em: 6 fev. 2017. 